Nathaniel W. Yang, MD ${ }^{1,2}$

${ }^{1}$ Department of Otorhinolaryngology College of Medicine - Philippine General Hospital University of the Philippines Manila

2Philippine National Ear Institute National Institutes of Health University of the Philippines Manila
Correspondence: Nathaniel W. Yang, MD Department of Otorhinolaryngology Ward 10, Philippine General Hospital Taft Avenue, Ermita, Manila 1000 Philippines

Phone: (632) 5264360

Fax: (632) 5255444

Email: nwyang@gmx.net

Reprints will not be available from the author.

\section{Demineralization of the Otic Capsule in Otosclerosis (Otospongiosis)}

A 34-year-old Filipina presents with bilateral progressive hearing loss and tinnitus of three years' duration. Otologic examination reveals normal external auditory canals and tympanic membranes, with good tympanic membrane mobility on pneumatic otoscopy. Standard audiometric examination shows a bilateral moderate conductive hearing loss. Temporal bone CT imaging reveals the presence of a focal region of bone demineralization involving the dense bone of the otic capsule surrounding the cochlear lumen (Figure 1), a finding consistent with a diagnosis of active otospongiosis. The diagnosis was confirmed by visualization of an otosclerotic focus during transcanal middle ear exploration where stapedectomy with placement of a stainless steel stapes prosthesis was performed.

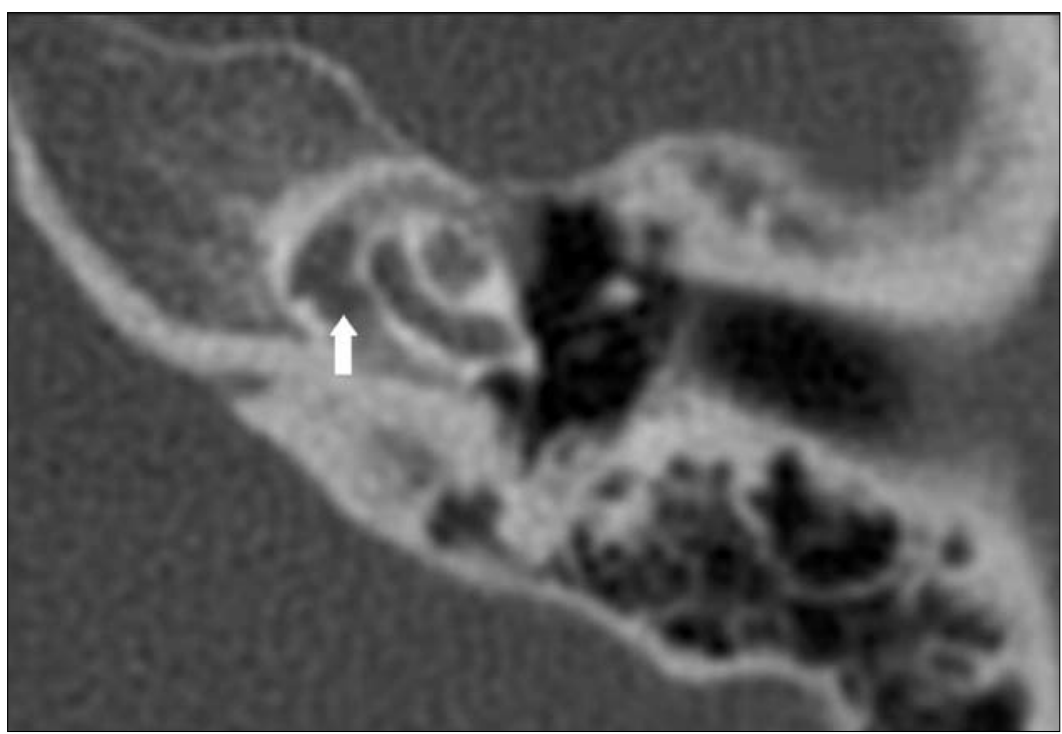

Figure 1. The white arrow is pointing to the area of focal demineralization surrounding the cochlea, a finding described as the "halo effect." 


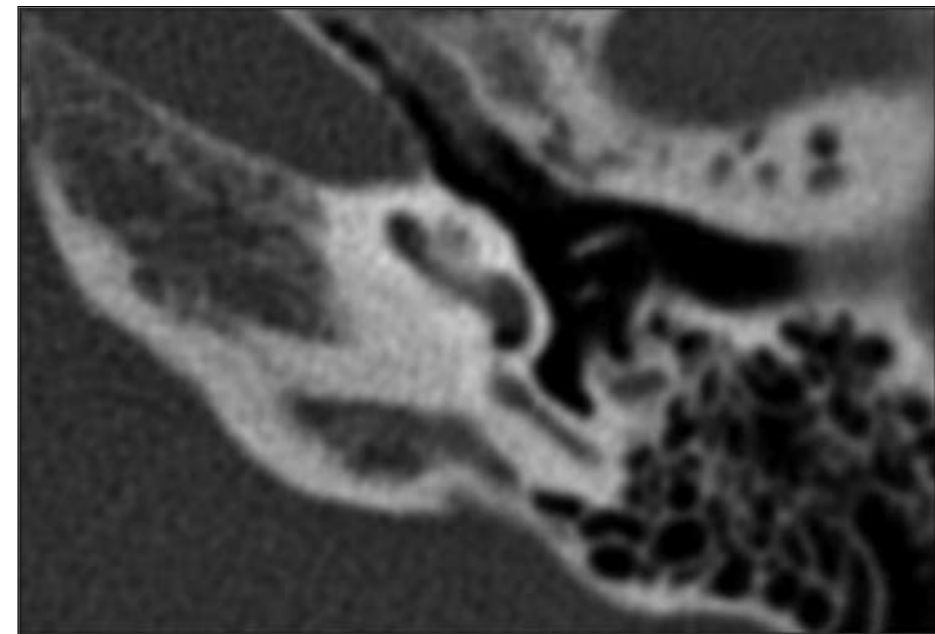

Figure 2. A normal temporal bone for comparison showing the dense bone surrounding the cochlear lumen

Otosclerosis is a condition unique to the temporal bone characterized by abnormal resorption and deposition of bone in the otic capsule and ossicles. Although it occurs more rarely in Asiatic populations compared to Europeans, Americans of Caucasian origin and Indians, it must be considered in patients presenting with primarily conductive hearing loss, especially if there is bilateral involvement. CT imaging of the temporal bone may help to differentiate this condition from other causes of conductive hearing loss such as tympanosclerosis and bony epitympanic fixation of the ossicular chain from chronic infection and inflammation of the middle ear. One must be cognizant of the fact that a normal temporal bone CT scan does not rule out a diagnosis of otosclerosis because an inactive, highly sclerotic focus that appears as a uniform hyperdense mass may be difficult to distinguish from the normal compact labyrinth capsule.' Other causes of otic capsule demineralization include osteogenesis imperfecta, Paget disease, otosyphilis and CamuratiEngelmann disease. These may be differentiated by their individually characteristic patterns of bone involvement and evidence of disease in other organ systems. ${ }^{2}$
1. Häusler R. Advances in stapes surgery. In : Jahnke K, editor. Middle ear surgery recent advances and future directions. Stuttgart: Thieme; 2004. p. 96-133.

2. Alkadhi $H$, Rissmann D, Kollias SS. Osteogenesis imperfecta of the temporal bone: $C T$ and MR imaging in Van der Hoeve-de Kleyn syndrome. Am J Neuroradiol $2004 \mathrm{Jun} / J u l_{;}$ 25:1106-1109. 